\title{
Skin cancer: an overview regarding treatment and its cosmetic repair
}

\begin{abstract}
Skin malignancies are very common. Among them, the commonest one is the Basal Cell Carcinoma (BCC). Although there is many forms on it treatment, in our opinion nothing substitutes the surgical approach. In only one session is possible to remove the tumor and correct the defect, having many different forms of flaps or grafts, getting good results. For this procedure we propose the term Cosmetic Cutaneous Oncology.
\end{abstract}

Keywords: basal cell carcinoma, electrodessication, sun exposure, cryosurgery, clavulanic acid
Volume 2 Issue 3 - 2018

\author{
Enrique Hernández Pérez,' José Enrique \\ Hernández Pérez, ${ }^{2}$ Mauricio Hernández \\ Pérez ${ }^{2}$ \\ 'Director, Center for Dermatology and Cosmetic Surgery, El \\ Salvador \\ ${ }^{2}$ Associated Professor, Center for Dermatology and Cosmetic \\ Surgery, El Salvador
}

\begin{abstract}
Correspondence: Enrique Hernández Pérez, Director, Center For Dermatology and Cosmetic Surgery, Villavicencio Plaza, Suite 3-I and 3-2, San Salvador, El Salvador, Tel 5032264 2240, Email drenrique@hernandezperez.com
\end{abstract}

Received: December 13, 2017| Published: June 05, 2018

\section{Introduction}

Skin cancer continues being very common, Instead of continuous appeals to protect the skin from the solar damage; in our surgicenter we operate at least 3 to 4 cases a week. We insist to our patients as verbally as in the screens of our waiting room, as and in brochures that genetics is the main and unavoidable cause of the problem, but sun exposure is the other causal problem. However, "the sunny beaches are so attractive..."

Basal cell carcinoma is the most frequently observed, and fortunately if the patient consults early, the cure is the rule; around $80 \%$ of all cutaneous malignancies are of this type. ${ }^{1}$ At the beginning of our formation as dermatologists we learned to treat basal cell carcinomas using curettage and electrodessication; then, in the decade of $80^{\prime}$ 's it was the turn of cryosurgery. At that moment we thought that we were in the right way. At the present time, ${ }^{1}$ however, our form of thinking is that among the multiple forms of treatment, our preferred, with no discussion, is the surgical one. Is the only one who allows us not only to remove the tumor, but to study in depth the margins around it? Even more: generally is possible to perform the tumor removal and its cosmetic repair at once, in only one session (Figures 1-6). ${ }^{2-5}$

Prior to the $60^{\prime} \mathrm{s}$, Dermatologists were considered as the masters in clinical diagnosis, but the surgical removal was left in the hands of surgeons of other specialties, mostly plastic ones. Great dermatologists with a superb surgical skills burst in the field of dermatologic surgery and paved the way for hundreds of colleagues who, following their steps showed us the techniques most important to treat, first the skin tumors and then all the universe of Cosmetic surgery. ${ }^{4}$ Names of Ted Tromovitch, Sam Stegman, Perry Robins and Larry Field, among others, are reminded with special gratitude for all of those working in cutaneous surgery.

\section{From the diagnostic to treatment}

The first step is the microscopic confirmation of the diagnostic. A
$3 \mathrm{~mm}$ punch biopsy is a must. And those oriented to surgery have to know also at least the basis of the microscopic aspect of the tumors, as well as the form of staging with prognostic purposes. ${ }^{1,2,4}$ The general principles are the same for all surgical procedures. Given that most of the patients harboring these tumors are seniors, it is convenient be sure that doesn't exist any problem with the use of local anesthesia: as the majority of tumors are placed on the face, we prefer always use epinephrine in the local anesthesia. Nevertheless, it is necessary never forget the interaction epinephrine-beta blockers. ${ }^{1}$ No matter the amounts, such drug interaction could carry to lethal consequences..$^{1,2,4}$ If the patient is using this drug (heart diseases, migraine), it must be stopped or changed for another one, previous consultation with the cardiologist, from who we demand a written statement. As local anesthesia, we use lidocaine plus epinephrine $(0.5 \%$ and 1 in 400.000 respectively) below and around the tumor mass. In the rest of the area, we use tumescent anesthesia, prepared at the moment; in general $100 \mathrm{cc}$ at all is enough, even in large flaps. ${ }^{5-9}$

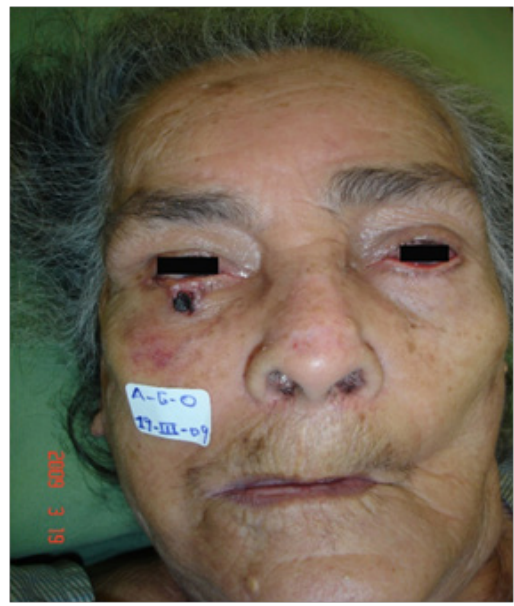

Figure I An 87 years old with a BCC in her right eyebrow. Note an age related ectropion at her left eyebrow. 


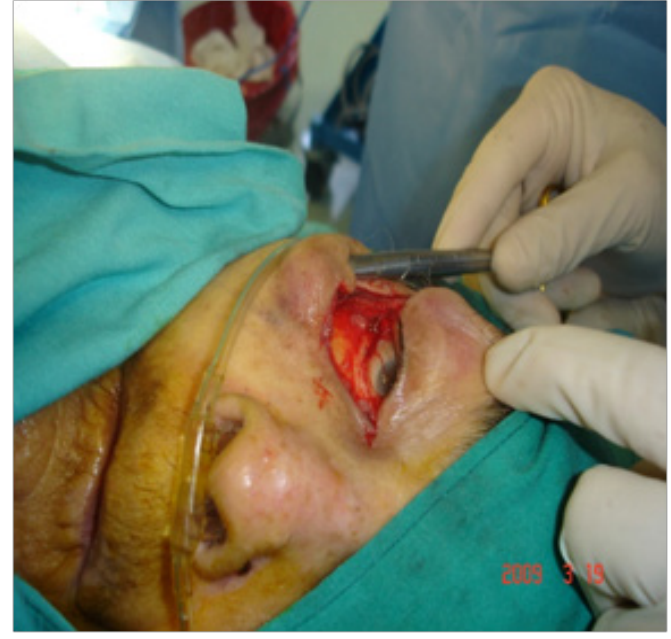

Figure 2 Tumor has been removed. The undermining is very wide, outlining an MUSTARDÉ flap, with the matter to avoid an ectropion.

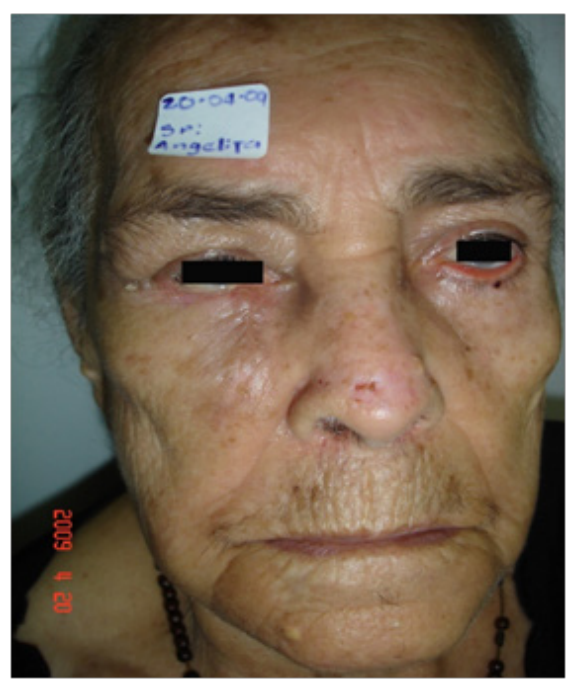

Figure 3 Two weeks later. Scar is barely noticeable. Compare with the senile ectropion at her left eyebrow.

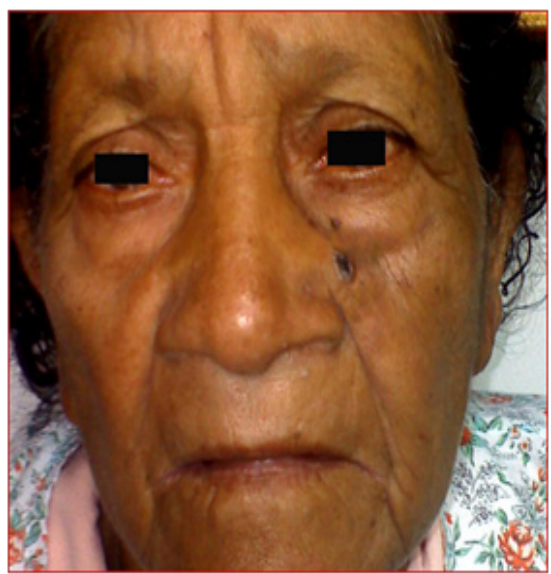

Figure 4 A 79 years-old lady with a BCC in her left cheek, at the junction with the eyebrow.

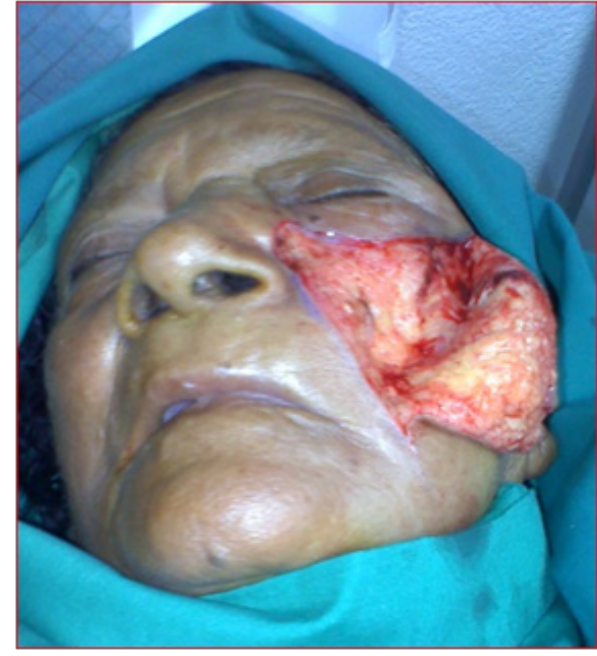

Figure 5 A wide undermining is performed, looking for an IMRE flap.

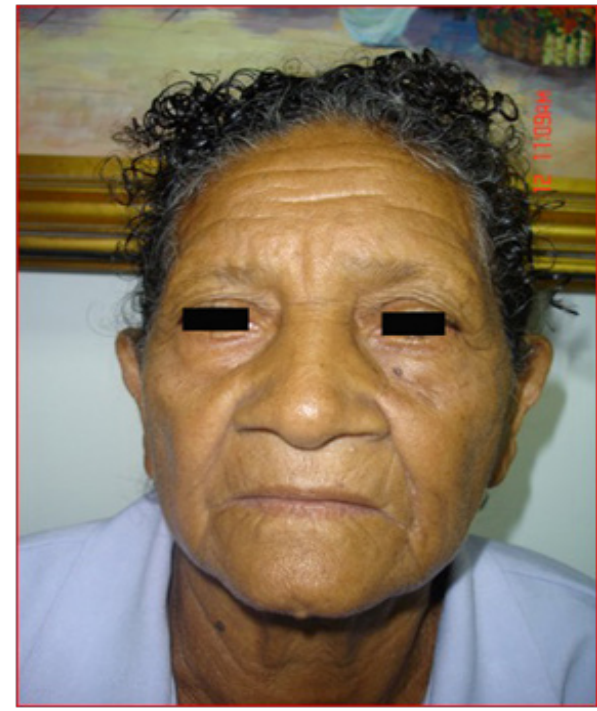

Figure 6 Two weeks later. Scar is almost imperceptible.

With the matter to avoid unpleasant memories because of surgery, we operate most of our patients under IV sedation, administered by a certified anesthesiologist. Midazolam and Fentanyl are the commonest drugs. Also here we consider necessary for the surgeon to know the properties, doses, and side effects of the medications. ${ }^{1}$ At the end, the surgeon is the captain of the ship, being certainly responsible of the end results. Preoperatory antibiotic, yes or no? Discussion regarding its value in clean surgeries is certainly open, but everybody use it. We prefer oral amoxicillin plus clavulanic acid starting one day before and keep along 5 days at all. In case of allergy, we change to ceftriaxone 1 gIM 1 hour before.

\section{Remotion of the tumor}

The intention is the removal of the tumor and its cosmetic repair in only one session. And that is possible in most of the cases. ${ }^{1,10}$ The forms to accomplish satisfactorily both aims are open for any surgeon owning enough skillness and creative mind. Skillness really is increased with practice and escapes from the aim of this short paper. 
The following photographs are showed only to illustrate some flaps, in the manner of a sample, which is possible to reach in a private surgicenter. At the end, we may coin the term Cosmetic Cutaneous Oncology.

\section{Acknowledgements}

None.

\section{Conflicts of interest}

The authors declared that there are no conflicts of interest.

\section{References}

1. Hernández Pérez E. Temas Selectos en Cirugía Cosmética. 1st ed. Mexico: Odontomedi; 2012. 365 p.

2. Borges AF. Elective Incisions and Scar Revision. Boston: Little Brown \& Company; 1973.

3. Baker SR. Local Flaps in Facial Reconstruction. 2nd ed. Michigan: Elsevier Mosby; 2008.
4. Tromovitch TA, Stegman SJ, Glogau RG. Flaps and Grafts in Dermatologic Surgery. Marshall: USA; 1989.

5. Weerda H. Reconstructive Facial Plastic Surgery. Freiburg: Germany; 1999.

6. Steinkogler FJ, Scholda CD. Results of basal cell carcinoma surgery of the eyelids. Fortschr Ophtalmol.1991;88(1):416-418.

7. Glud M, Orniand SH, Gniadecki R. Basal cell carcinoma surgery. Ugeskr Laeger. 2016;178:603-609.

8. Baba M, Durdu M, Seckin D. A useful alternative approach for the treatment of well demarcated Basal cell carcinoma: Surgical excision and margin control with Tzanck smear test. Dermatol Surg. 2010;36(5):659-654.

9. Carducci M, Betti R. Basal cell carcinoma:surgical margin detection using digital dermoscopy. Dermatol Surg. 2012;38(6):964-965.

10. Boitor R, Kong K, Shipp D, et al. Automated multi modal spectral histopathology for quantitative diagnosis of residual tumour during basal cell carcinoma surgery. Biomed Opt Express. 2017;8(12):5749-5766. 